\title{
Clinical Trials Database
}

National Cancer Institute

\section{Source}

National Cancer Institute. Clinical Trials Database. NCI Thesaurus. Code C16077.

Mandated by the FDA Modernization Act of 1997. An NIH-wide database of information about federally and privately funded clinical trials regarding serious or life-threatening diseases or conditions. 